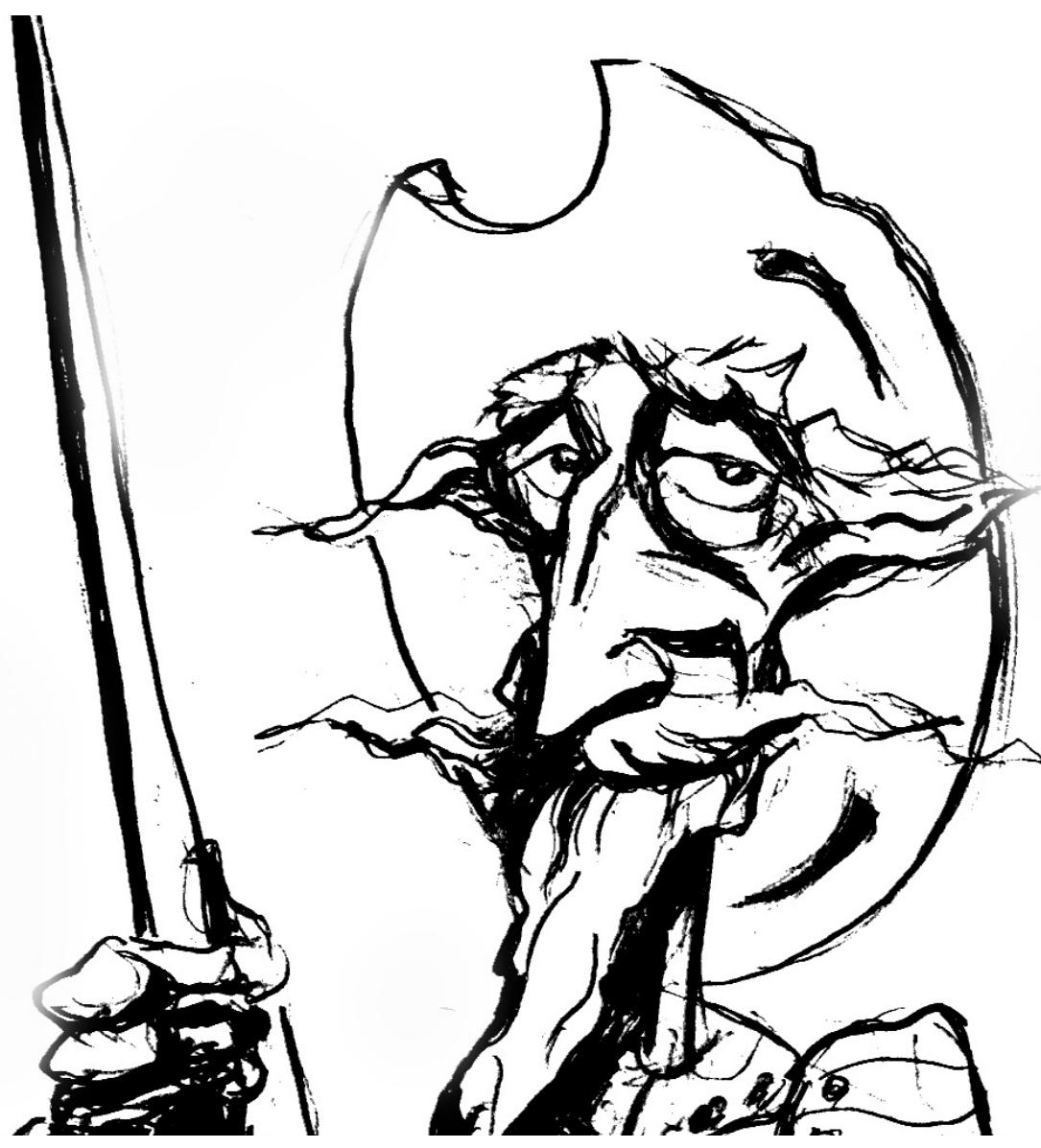

El caso del supuesto Klan Radical. Arqueología de una vida pública agonística (1929)

[Marianne González Alemán] 



\title{
El caso del supuesto Klan Radical. Arqueología de una vida pública agonística (1929)*
}

\author{
The Case of so-called Klan Radical. An Agonistic Public Life Archeology (1929)
}

\author{
MARIANNE GONZÁLEZ ALEMÁN
}

\section{Resumen}

El presente artículo reconstruye los contornos de una enigmática entidad, el Klan Radical, cuyo nombre invadió las calles de la ciudad de Buenos Aires en julio de 1929. El objetivo es abordar el supuesto Klan por lo que permite comprender de la vida pública de aquel entonces, de las concepciones de lo político y de la función que en ellas desempeñaba la violencia. El análisis de los discursos y prácticas de intervención política vinculados a la figura del Klan permite observar cómo se produjeron conexiones entre la dinámica beligerante en la calle, la prensa y en el parlamento, en el marco de una concepción estratégica y agonística de la acción cívica.

\section{Palabras clave}

Unión Cívica Radical; Yrigoyenismo; Republicanismo; Espacio público; Violencia Política

\begin{abstract}
This article reconstructs the contours of an enigmatic entity, the Radical Klan, whose name invaded the streets of the city of Buenos Aires in July 1929. The purpose is to approach the socalled Klan as a way of understanding the public life of that time, the conceptions of the political and the role that violence played in them. The analysis of the discourses and practices of political intervention linked to the figure of the Klan allows us to observe how connections between the belligerent dynamics in the street, the press and the parliament took place, within the framework of a strategic and agonistic conception of civic action.
\end{abstract}

\section{Key words}

Radical Civic Union; Yrigoyenism; Republicanism; Public Space; Political Violence

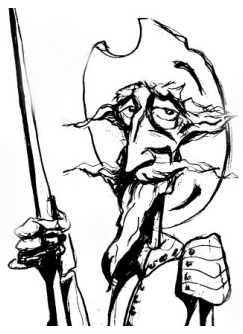

Recibido con pedido de publicación el 15 de mayo de 2020 Aceptado para su publicación el 10 de septiembre de 2020

Versión definitiva recibida el 2 de octubre de 2020

Marianne González Alemán, Instituto de Historia Argentina y Americana “Dr. Emilio Ravignani"- Consejo Nacional de Investigaciones Científicas y Técnicas / Universidad Nacional de Tres de Febrero, Buenos Aires, Argentina; e-mail: mgonzalezaleman@untref.edu.ar

\footnotetext{
*Agradezco los comentarios de los evaluadores anónimos de la revista

Esta obra se publica bajo licencia Creative Commons. Atribución-NoComercial-CompartirIgual 4.0 Internacional
} 
“Klan Radical (...) 100 x 100 de radicalismo". El 3 de julio de 1929, las calles céntricas de Buenos Aires amanecieron empapeladas con unos misteriosos afiches que anunciaban la formación de una entidad destinada a defender la causa de los argentinos. A partir de ese día, el Klan Radical se convirtió en una figura central de los discursos de la oposición a Hipólito Yrigoyen. El nombre del Klan era esgrimido para denunciar el arbitrario presidencial y responsabilizar a los radicales por la violencia en las calles. Después del golpe del 6 de septiembre de 1930, recordar las agresiones cotidianas de los klanistas en Avenida de Mayo o en Florida se convirtió en un tópico de los relatos ex post de los "revolucionarios" antiyrigoyenistas, pues semejante situación justificaba la "reacción cívica" de los que pretendían haber bregado por las libertades republicanas. Por su lado, los historiadores no han profundizado en el estudio del Klan. Su existencia ha tendido a ser naturalizada en los trabajos que lo mencionan tangencialmente para caracterizar el contexto de la segunda presidencia de Yrigoyen. "Fuerza de choque paramilitar" (Rock, 2010: 255), “Grupo de choque" (Horowitz, 2015: 246), las calificaciones retoman las denominaciones instaladas por los antiyrigoyenistas, en particular por los diarios Crítica y La Fronda, y remiten erróneamente a las formaciones militarizadas que en aquel entonces operaban en Europa. El presente artículo pretende precisar los contornos de esta enigmática figura, con el objetivo de abordar el supuesto Klan por lo que permite comprender de la vida pública de aquel entonces, de las concepciones de lo político y de la función que en ellas desempeñaba la violencia.

Es que los años 1928-1930 corresponden a una coyuntura de profunda crisis de definición de las reglas del juego democrático, así como de los sentidos y modalidades atribuidos a la participación ciudadana. Electo a principio de 1928 y aureolado con más del 57\% de los votos, Yrigoyen había interpretado su victoria en las urnas como un "plebiscito" que confirmaba la identidad entre su partido, la Unión Cívica Radical (UCR), y la "causa" de la nación argentina. En pocos meses, sin embargo, el entusiasmo y las expectativas suscitadas por el nuevo presidente cedieron lugar a una serie de conflictos que debilitaron rápidamente al gobierno y socavaron sus bases de adhesión en la opinión pública. Por un lado, porque los efectos negativos de la crisis económica mundial afectaron a la Argentina unos meses antes del crack de Wall Street, provocando el aumento de la inflación, el descenso de los sueldos y la disminución del ritmo del gasto público. Por otro lado, en el campo político-institucional, el segundo triunfo electoral del viejo líder radical representó un hito en un proceso más amplio de deslegitimación recíproca que venía exacerbándose desde 1916 entre el yrigoyenismo y la oposición (Mustapic, 1984). En ese marco, diversos sectores del espectro político empezaron a expresar desconfianza en la capacidad regeneradora de los instrumentos del sufragio tal como funcionaban desde 1912, frente a un partido al que adjudicaban los peores vicios y que resultaba invencible en las urnas. Hacia 1929, una parte muy amplia del escenario político argentino concluía que el supuesto fracaso de la 
experiencia abierta con la reforma electoral "hacía ineludible una intervención externa, bien fuese para reconstruir el orden republicano sobre bases que no serían ya las de la democracia de sufragio universal, bien - y era esta la alternativa preferida por los más - para recomenzar esa experiencia democrática sobre bases [que suponían] más sólidas" sin Yrigoyen (Halperin Donghi, 2007: 279).

En ese contexto inestable y conflictivo, la calle adquirió una importancia fundamental: se afirmó como un espacio público, como un espacio de representación y de exhibición de determinados comportamientos socialmente asociados a la ciudadanía, pero también como un espacio en disputa. Analizaremos, pues, las prácticas e interacciones violentas que se desplegaron en las calles porteñas, centrándonos en los actores colectivos vinculados al yrigoyenismo que fueron acusados de pertenecer al Klan Radical. Consideramos esta violencia de baja intensidad, no como una desviación, sino como parte integrante del juego político; una violencia "significante, codificada, controlada, modelada, en suma, una violencia cultivada" y compartida por determinada cantidad de actores (Lepoutre, 1997: 20). Se trata de reconstruir las prácticas, pero también de comprender las estructuras de valores y los códigos sociales a partir de los cuales los actores interpretaban y justificaban sus acciones y evaluaban las de sus pares. Estas estructuras delineaban los límites de los comportamientos aceptables e inaceptables, así como los contextos en los cuales la violencia era considerada como un recurso legítimo de la acción política. Nos centraremos también en el "pensamiento en acción" (Jaume, 2004) de los que tomaron parte de lo que podría entenderse como un conflicto por los contenidos de la república. El análisis de dichos discursos y prácticas de intervención política permite observar cómo se produjeron conexiones entre la dinámica beligerante en la calle, la prensa y el parlamento, en el marco de una concepción estratégica y agonística de la acción cívica. Estas facetas de la vida pública vinculadas a la tradición republicana han sido menos tomadas en cuenta por la historiografía dedicada a la entreguerra, la cual se centró en la cuestión electoral, en el sistema de partidos y en el funcionamiento de la vida institucional; sin embargo, permiten complejizar la comprensión del campo de lo político del período.

\section{La batalla por el Senado y la aparición del "Klan Radical"}

\section{Un contexto de polarización conflictiva}

En 1929, el conflicto entre el yrigoyenismo y sus adversarios se cristalizó alrededor de una cuestión institucional que implicó a dos provincias intervenidas el año anterior por el Poder Ejecutivo Nacional: San Juan y Mendoza. A partir de julio, el tema de la aceptación o del rechazo por el Senado de los diplomas de investidura de los antipersonalistas Federico Cantoni y Carlos W. Lencinas, respectivamente electos en estas dos provincias, se convirtió en un desafío central. Durante el primer mandato de Yrigoyen, el Senado había representado el bastión de la oposición - 
dueña de la mayoría de las bancas- que había tendido a obstaculizar los objetivos políticos del gobierno. Para el oficialismo, que denunciaba las condiciones dudosas y violentas en las que se habían efectuado las elecciones de ambos representantes del Cuyo, se trataba de conquistar la mayoría senatorial tras la organización de una nueva votación, en un contexto local más favorable a la victoria del yrigoyenismo. La posibilidad de revertir la relación de fuerzas en la Cámara Alta permitiría contrarrestar una parálisis legislativa que reflejaba cuánto el parlamento se había convertido en un campo de lucha entre dos bandos irreductibles. Por otra parte, la impugnación de los cargos senatoriales de Cantoni y Lencinas se sustentaba en una interpretación del "mandato histórico" de Yrigoyen que hacía del presidente el depositario de la voluntad del pueblo y de sus aspiraciones a la regeneración democrática. Del lado de la oposición en cambio, el apoyo a las figuras controvertidas de los senadores cuyanos apuntaba a la conservación del último reducto que dominaba. A su vez, la cuestión de los diplomas ofrecía a los antiyrigoyenistas la oportunidad de erigirse retóricamente en "defensores" de las instituciones republicanas.

La batalla por el Senado acentuó la polarización de la lucha política, la cual se manifestó en varios escenarios públicos entrelazados. En las provincias de San Juan y Mendoza, las intervenciones dieron lugar a hechos de violencia entre los emisarios del ejecutivo nacional y los partidarios de los gobernadores depuestos. En el Parlamento, los debates tumultuosos sobre la atribución de los diplomas cuyanos monopolizaron la actividad de los legisladores. Al mismo tiempo, las crónicas de los diarios contribuyeron a alimentar el clima de efervescencia alrededor del acontecimiento y a convertir al palacio del Congreso en el corazón de la vida pública nacional. La prensa, volcada unánimemente al bando antiyrigoyenista, reprodujo con énfasis y parcialidad los discursos legislativos, las opiniones de referentes partidarios y los acontecimientos vinculados al debate. No obstante, las calles de Buenos Aires fueron el espacio donde se produjo el combate político más arduo. Allí las palabras se cargaban de una dimensión performativa que las diferenciaba poco de los actos.

Por un lado, la cuestión de los diplomas fue el detonante de una intensa campaña de los sectores más adversos al gobierno, los cuales apuntaron a crear un clima tangible de "agitación cívica" contra lo que calificaban como las acometidas de la "tiranía" de Yrigoyen. Este conjunto heterogéneo de actores colectivos compuesto por los radicales antipersonalistas, la Liga Patriótica Argentina (LPA), los nacionalistas de la Liga Republicana (LR) y el Partido Socialista Independiente (PSI)- focalizó sus esfuerzos en "ganar las calles" del centro. A través de la reactivación de una serie de consignas, símbolos y prácticas, pusieron en primer plano una retórica republicana que exaltaba la acción como virtud cívica y como forma de intervención legítima de los ciudadanos erguidos en amparo de las instituciones (González Alemán, 2012). Por otro lado, desde 2 de julio, primer día de los debates, las miradas se centraron en la Plaza del Congreso y en el público que se 
aglutinaba en las puertas del senado para asistir a las deliberaciones. Rápidamente, las inmediaciones del edificio parlamentario reprodujeron en actos los términos de un enfrentamiento político que superaba los aspectos legislativos. Es en este contexto que entró en escena el nombre del "Klan Radical".

Reconstruir el perfil del Klan no es tarea fácil. En primer lugar, porque este no corresponde ni a una organización estructurada, ni a una formación cuya existencia haya sido oficialmente comprobada. Por lo tanto, no existe documentación que permita rastrear huellas tangibles ni de su constitución, ni de sus modalidades de funcionamiento. En segundo lugar, las menciones de su existencia suelen aparecer en la prensa opositora, en especial en Crítica y La Fronda que, con tono estridente y procedimientos efectistas, estaban fuertemente involucrados en las campañas antiyrigoyenistas. En su construcción de la figura de los "klanistas", el diario de Botana apelaba a narrativas próximas a la crónica policial de la época, caracterizada por relatos en los cuales "se cuenta aquello que, por falta de datos, es preciso imaginar" (Saítta, 2013: 198; Tato, 2004). Por lo tanto, se hace difícil desenredar lo que, en los discursos periodísticos, atañe a hechos verídicos, al sensacionalismo de la prensa comercial o a una estrategia destinada a desacreditar al gobierno y sus seguidores.

Algunas menciones de contemporáneos en escritos posteriores permiten recopilar informaciones dispersas sobre la entidad. Sin embargo, estos autores pertenecieron al bando opuesto al yrigoyenismo, por lo que tendieron a retratar al grupo bajo los rasgos de una "tropa de choque criminal" cuya evocación servía para confirmar el carácter supuestamente dictatorial del segundo mandato de Yrigoyen. Los autores radicales, por su lado, niegan la existencia del Klan. ${ }^{1}$ Finalmente, una investigación judicial realizada luego del golpe de 1930 ofrece elementos sobre las actividades de los radicales sospechados de pertenecer a dicha agrupación. No obstante, el expediente es poco equilibrado ya que el fiscal se ocupó de reunir solo las pruebas acusatorias en pos de demostrar la existencia de una "asociación ilícita" radical. A pesar de los límites impuestos por las fuentes, es interesante detenerse en los contornos imprecisos de este supuesto grupo y en su contexto de emergencia. Real o fantaseado, el fenómeno permite reflexionar sobre la radicalización de las prácticas políticas que, en 1929, tuvieron la calle como principal escenario.

\section{El fantasma del "Klan"}

La primera mención del "Klan Radical" apareció en julio de 1929, en el momento en que la opinión pública focalizaba su atención en los debates sobre los diplomas cuyanos. El 2, la apertura de la sesión parlamentaria fue acompañada por incidentes provocados por militantes yrigoyenistas que pretendieron exhibir su fuerza

\footnotetext{
${ }^{1}$ Oyhanarte, Horacio (1932). Por la patria, desde el exilio digo, Biblioteca "Democracia Radical", Buenos Aires, p. 101.
} 
numérica dentro y fuera del recinto. Entre el público amontonado en las puertas del Palacio legislativo, grupos de partidarios del presidente hicieron notar su presencia por sus vivas constantes a Yrigoyen y por forzar la entrada del Congreso². Diputados de la UCR de la Capital, como Leopoldo Bard o Juan Carlos Hiriart, parecían liderar la acción. ${ }^{3}$ Algunos senadores de la oposición que intentaron deslizarse entre el público para penetrar en el interior del palacio fueron insultados e increpados por yrigoyenistas agrupados en la entrada. ${ }^{4}$ Se improvisaron varias tribunas en las calles adyacentes. Los oradores exhortaron a su audiencia a apoyar a los senadores personalistas y calificaron a Cantoni y Lencinas "con los más gruesos adjetivos". ${ }^{5}$ En este contexto tenso, los legisladores levantaron la sesión, lo que motivó la organización de una manifestación de partidarios del presidente en la Avenida de Mayo. Según el diario yrigoyenista La Época, el desfile se efectuó "sin proferir expresiones ofensivas", para La Nación, se escucharon mueras a Cantoni y se hizo "ostentación de armas de fuego". ${ }^{6} \mathrm{Al}$ llegar a la altura de la sede de Crítica, los manifestantes recibieron trozos de hierro y letras de plomo que fueron arrojados desde los balcones del diario. ${ }^{7}$

A primera vista, las escenas son características del estilo ofensivo que la barra radical solía adoptar para hacer presión sobre el resultado de los debates importantes tratados en el Parlamento. Sin embargo, adquirieron otra dimensión cuando, al día siguiente, el nombre del "Klan Radical" apareció por primera vez en unos afiches que cubrían las paredes de la ciudad:

\section{“El Klan Radical, \\ DECLARA, PÚBLICAMENTE,}

que la aprobación de los diplomas de San Juan y Mendoza, significaría

legalizar el crimen y el latrocinio.

\section{EL SENADO RECHAZARÁ ESOS DIPLOMAS}

o tendrá que enfrentar a muchos argentinos, dispuestos al sacrificio en salvaguardia de la dignidad nacional.

Aspiración del K. R.

100 x 100 de RADICALISMO" ${ }^{8}$

\footnotetext{
${ }^{2}$ La Época, 04/07/1929, p. 1

${ }^{3}$ Libertad!, 03/07/1929, p. 1.

${ }^{4}$ La Nación, 03/07/1929, p. 1.

${ }^{5}$ La Vanguardia, 03/07/1929, p. 1-2.

${ }^{6}$ La Época, 03/07/1929, p. 1

${ }^{7}$ La Calle, 04/07/1929, p. 1.

${ }^{8}$ Crítica, 04/07/1929, p. 3 . En Crítica de ese mismo día se encuentra una fotografía del afiche pegado en una pared de la ciudad.
} 
A partir de ese momento, el espectro del Klan dominó el escenario público. En primer lugar porque la especulaciones sobre su existencia potenciaron la resonancia mediática de la acción manifestante de los radicales que, en cada una de las sesiones dedicadas a los diplomas, afirmaban su presencia colectiva en la Plaza del Congreso. El 4 de julio por ejemplo, entre 30 y 50 radicales personalistas se posicionaron en las puertas del Parlamento e insultaron al defensor de los senadores de Cuyo, Leopoldo Melo. Según Crítica, todos los días, "un numeroso núcleo de elementos de comité tomaba posesión de la acera principal del Congreso". Solían "rodear una bandera" para "discutir de cuestiones políticas" en forma "agresiva y perturbadora". ${ }^{9}$ El 5 de julio, en un artículo titulado "Nuestro cartel", el diario yrigoyenista La Calle declaraba que frente al Congreso había "un puesto de honor para cada argentino honrado" dispuesto a "proteger la patria" de los "traidores"10. En segundo lugar, los diarios se apoderaron del episodio de los afiches para proyectar en la entidad una serie de fantasías que la convirtieron en el arquetipo de lo que los opositores aborrecían en la "chusma" radical. En tercer lugar, durante los meses siguientes, varios incidentes provocados por yrigoyenistas contra movilizaciones opositoras fueron interpretados por la prensa como la confirmación de la existencia de un grupo de acción. En consecuencia, es indispensable partir de la confusión entre el "Klan imaginado" y la realidad de la agitación política en la calle para poder aprehender la enigmática organización ante todo por lo que revela sobre el clima político de 1929. Tal aproximación permite acceder a una situación compleja, a mitad de camino entre, por un lado, la imagen difundida por los medios y, por el otro lado, la negación de su existencia por parte de los integrantes de la UCR.

Según algunos contemporáneos de los hechos como Jorge Luis Borges y Arturo Jauretche, los afiches del Klan no fueron otra cosa que el producto de una broma del poeta peruano y aprista, Alberto Hidalgo, entonces afín a Yrigoyen, empleado de la Intendencia Municipal y cuya personalidad provocadora era conocida de los círculos literarios (Borges, 2011: 60; Jauretche, 2002: 66). El componente irónico del afiche es por lo menos evidente cuando se toma en cuenta la última línea de los afiches: "100 x 100 de radicalismo". La expresión remitía al lema "100 x 100 de americanismo" del Ku Klux Klan que se había convertido en un movimiento de masas poderoso en Estados Unidos. Dicha organización racista ocupa un lugar central en la novela de Roberto Arlt, Los siete locos editada en octubre de 1929. Previamente, en julio de 1928, Arlt había adelantado el capítulo titulado "La sociedad secreta" en la revista Pulso que dirigía Hidalgo (Arlt, 1928).

El aspecto satírico también está presente en el semanario proyrigoyenista titulado Klan Radical que fue fundado en diciembre de 1929 por Eladio Mendivil, director de las revistas Cinema Chat y Vida porteña, y del diario Radical. En el

\footnotetext{
${ }^{9}$ Crítica, 26/07/1929, p. 5.

${ }^{10}$ La Calle, 05/07/1929, p. 1.
} 
expediente judicial, el periodista afirma haber elegido dicho título en forma oportunista en un momento en que Radical enfrentaba problemas económicos. El nuevo periódico de tono combativo llevaba el encabezamiento "Klan Radical, el fantasma de las ligas y patoteros", jugando con el carácter ambiguo de esta figura entre imaginaria y amenazante. ${ }^{11}$

La investigación realizada por la justicia después del golpe de 1930 consta de un reglamento secreto cuyo texto, datado del 25 de mayo de 1929, es tomado como prueba de la constitución formal de la supuesta entidad. ${ }^{12}$ No obstante, se trata de la copia dactilografiada de un legajo de la División de Investigaciones de la Policía Federal, por lo que es imposible comprobar su veracidad, ni su origen. En su crónica de la "Revolución" de Septiembre, Beresford Crawkes afirma que los miembros del famoso clan utilizaban una insignia distintiva (un botón redondo dividido en dos

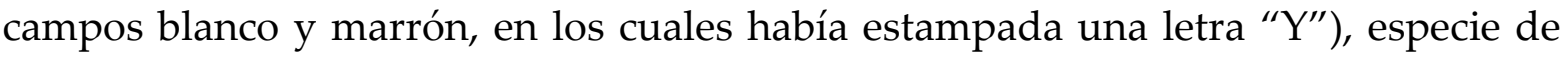
salvoconducto que les permitía gozar de la benevolencia de la policía cuando tomaban la calle. ${ }^{13}$ Dicho distintivo se encuentra abrochado en una de las fojas del sumario "Klan Radical". La investigación policial pudo comprobar que unas 5000 copias fueron encargadas a una fábrica de medallas del centro por el subadministrador del diario La Época, Felix Foulier, a fines de julio de 1930. El mismo Foulier expresó que el pedido se había realizado en el marco de la preparación de una manifestación prevista para el 20 de septiembre del mismo año y fue solicitada por Pacífico Rodríguez Villar, entonces secretario de la Municipalidad de Buenos Aires. A principios de septiembre de 1930, otra persona llamada Enrique de Eboli concurrió a la misma casa y adquirió cien de esos botones. ${ }^{14}$

Varios testimonios incluidos en el expediente señalan que Eboli fue el autor de un manifiesto repartido por la ciudad el 3 de septiembre, cuando la perspectiva de golpe se hacía amenazante. Un original del volante se encuentra en la causa. El documento llama a instaurar el Estado de sitio y la ley marcial, a "poner todo el poder público en manos del presidente" y a clausurar los diarios opositores. El texto agrega: "El pueblo radical irigoyenista (sic) debe pedir que el ilustre jefe le 'suelte las manos' para poder obrar libremente contra la oposición, en las calles de Buenos Aires". ${ }^{15}$ Es por ello que el Klan Radical es asociado de manera a veces confusa a dos momentos políticos distintos: por un lado, la pelea callejera de la segunda mitad de 1929 alrededor de los diplomas de Cuyo; por el otro, los intentos aislados de

\footnotetext{
${ }^{11}$ Archivo General del Poder Judicial de la Nación Argentina [AGPJ], "Eboli, Enrique Fernando María y Lopez Serrot, Oscar", Sentencia en lo Criminal letra "D” [Eboli], cuerpo 2, fojas 350-356.

12 AGPJ , Eboli, cuerpo 4, fojas 726-728.

${ }^{13}$ BERESFORD CRAWKES 533 días de historia argentina, Imprenta Mercatali, Buenos Aires, 1932, p. 254. La Nación también menciona la existencia de una insignia (03/10/1930, p. 1-2).

${ }^{14}$ AGPJ , Eboli, cuerpo 2, fojas 356-362.

${ }^{15}$ AGPJ , Eboli, cuerpo 3, fojas 621-622.
} 
algunos radicales para contrarrestar, a veces con armas, el clima abiertamente golpista de principios de septiembre de 1930.

Cuando se referían a las actividades del Klan, los diarios opositores solían señalar la participación de notables representantes de la UCR de la Capital. En reiteradas oportunidades, los agentes de policía también registraron la presencia de diputados y senadores en los lugares donde grupos de yrigoyenistas provocaron incidentes. ${ }^{16}$ La complicidad de Leopoldo Bard, Pedro Cagnoni, Pedro Bidegain o Diego Luis Molinari, entre otros, solía ser motivo de repetidas denuncias de la prensa que los acusaba de reclutar miembros del Klan entre los afiliados de los comités y empleados de ciertas agencias de la administración. ${ }^{17}$ El nacionalista Federico Ibarguren sostiene que esta "gente armada del comité, con boinas blancas", ostentaba "agresivas leyendas y banderas partidarias" desde vehículos pertenecientes a administraciones públicas como el Correo y los Ferrocarriles. ${ }^{18}$ De hecho, en marzo de 1931, un informe del fiscal Barberis permite observar que todos los inculpados por ser integrantes del clan eran empleados públicos de las empresas de Ferrocarril, del Correo o de la Municipalidad de Buenos Aires. ${ }^{19}$ A su vez, varios agentes policiales reconocieron a Angel Molinari, Manuel Ares de Parga y Antonio Sturla como cabecillas que "se dedicaban a excitar los ánimos" de sus correligionarios cuando se avecinaba una refriega callejera. ${ }^{20}$ El primero era el hermano del famoso senador yrigoyenista y trabajaba como empleado de la Administración General de Sellos, el segundo se desempeñaba como Inspector del Banco Hipotecario Nacional, el tercero era secretario del administrador de los Ferrocarriles del Estado y subdirector del tráfico de la Municipalidad. Sturla era además presidente del Subcomité "Lucha y Lealtad" con sede en la calle Thames 2438, cuyos integrantes eran en su mayoría empleados de los Ferrocarriles. ${ }^{21}$

Las personas acusadas de pertenecer al Klan trabajaban en ramas de la administración que tienen especial significación para el análisis. A partir de 1916, los gobiernos radicales usaron los recursos públicos para crear cargos en la administración estatal y nombrar empleados en función de criterios políticos, con el objetivo de generar lazos de lealtad y conseguir su participación en actividades partidarias (Rock, 1972; Horowitz, 2015: 89-124). El segundo mandato de Yrigoyen coincidió con despidos en la municipalidad de Buenos Aires y con el nombramiento de 6828 personas, por lo que la cifra de empleados municipales aumentó en 3951 (Horowitz, 2015: 584). El Correo representaba una de las agencias estatales que reunía los mayores porcentajes de funcionarios del partido en sus oficinas. De

\footnotetext{
${ }^{16}$ La Nación, 17/10/1929, p. 1-5 y 18/10/1929, p. 1-5; Crítica, 19/10/1929, p. 1

${ }_{17}$ Crítica, 19/10/1929, p. 1; La Nación, 22/08/1930, p. 26.

${ }^{18}$ IBARGUREN, Federico Orígenes del nacionalismo argentino, Celsius, Buenos Aires, 1969, p. 43.

${ }^{19}$ La Nación, 03/10/1930, p. 1-2; AGPJ , Eboli, cuerpo 3.

${ }^{20}$ AGPJ , Eboli, cuerpo 1, fojas 122-150. Los nombres aparecen en partes policiales de $1929 \mathrm{y}$ los tres individuos fueron reconocidos por agentes en rondas de reconocimiento en 1930.

${ }^{21}$ AGPJ , Eboli, cuerpo 3, foja 462.
} 
hecho, en 1922, algunas semanas antes de que finalizara su primer mandato, Yrigoyen había nombrado 4000 empleados supernumerarios que no fueron despedidos durante el gobierno de Alvear (Persello, 2001). Correos y Telégrafos era una repartición tradicionalmente asociada al clientelismo electoral y era común en las crónicas de los diarios opositores la referencia a los carteros "uniformados" de las manifestaciones radicales.

Asimismo, muchos de los dirigentes personalistas que accedieron a cargos políticos en 1928 habían construido su carrera a partir del control del aparato partidario en un distrito electoral porteño (Rock, 1972: 249). Era el caso de los legisladores que fueron señalados como instigadores del Klan. Todos ellos seguían presidiendo un comité y/o mantenían vínculos directos con caudillos barriales: Pedro Podestá presidía el comité de la $2^{\underline{a}}$ sección, Hector Bergalli el de la $5^{\underline{a}}$ (la "Quinta de Fierro", tradicionalmente fiel al radicalismo). El concejal Francisco Turano era un dirigente importante de la sección Balvanera Oeste. En cuanto a Bidegain, era influyente en la $6^{\mathrm{a}}$ sección donde era presidente del Club de Football San Lorenzo y del Club Social Mariano Boedo.

Hasta aquí, los elementos recopilados no confirman la existencia de un grupo de acción secreta yrigoyenista, ni mucho menos de una tropa de choque orgánica comparable a las milicias políticas de los partidos europeos de la misma época. Revelan más bien el peso ejercido por los "hombres de comité" - es decir por los individuos involucrados en la red clientelar radical de la Capital - sobre una dinámica política cada vez más polarizada y radicalizada. Estas modalidades no eran nuevas, pero en 1929 se caracterizaron por un mayor grado de movilización de los afiliados más activos, en un momento en que grupos de opositores también se organizaban como "fuerzas de acción" para "ganar la calle".

\section{"Ganar la calle": honor, virilidad y violencia}

\section{Una secuencia inédita de enfrentamientos}

La contienda se exacerbó a partir de octubre de 1929. El centro de la capital se convirtió en el escenario cotidiano de la movilización de los sectores más exaltados de la oposición. Las acciones colectivas -que apelaban a la "defensa de la República" para justificar un llamado cada vez menos implícito a recurrir al campo extrainstitucional- respondían a una lógica de conquista del espacio público y suscitaron en retorno la reacción frontal de partidarios de la UCR que procuraron conservar el control del espacio urbano. En ese clima, la figura del Klan volvió a convertirse en un tópico omnipresente del que la oposición se apoderó para magnificar la sensación de desorden y acusar a Yrigoyen de dictador. Una secuencia significativa de este proceso es la de octubre-diciembre de 1929, de la que solo expondremos algunos momentos claves para el análisis, circunscriptos al mes de octubre. 
El 6 de octubre, en ocasión de la asamblea anual de la LPA, el presidente de la organización, Manuel Carlés encendió la mecha con un discurso en el que anunciaba que había sonado la "hora de la vindicta". Los argentinos tenían el "deber" de optar definitivamente entre la "patria" y un gobierno que no respetaba la ley. El jefe de la Liga oponía lo que llamaba la "vindicta histórica" -es decir la defensa del "honor cívico" que, desde la Revolución de Mayo caracterizaría al pueblo argentino en su combate contra los "tiranos"- a "la mayoría electoral", "invocada falsamente [por el presidente] para demostrar su "mandato histórico'". ${ }^{22} \mathrm{Al}$ día siguiente, varios carteles titulados "La hora de la vindicta" fueron pegados en las paredes de la ciudad y volantes con el texto del discurso de Carlés fueron repartidos en las calles. $^{23}$

El día 13, la LR realizó un mitin en la Plaza del Congreso. Durante el acto, los oradores de la Liga fueron interrumpidos por disparos de petardos lanzados por yrigoyenistas desde las esquinas de la plaza. Cuando Francisco Uriburu, dueño del diario La Fronda, tomó la palabra, se oyeron disparos de revolver que provocaron un tumulto y varias corridas. Finalizado el acto, el público allí reunido formó una manifestación con el objetivo de dirigirse hacia la calle Florida. A la altura de la sede de La Fronda, la columna se detuvo un tiempo para escuchar a diversos oradores ubicados en los balcones del edificio. Luego, la misma retomó su marcha hacia la Avenida de Mayo. Al pasar por las oficinas de La Prensa, los manifestantes le tributaron una ovación, mientras que, algunas cuadras después, La Época fue objeto de una silbatina. Pocas cuadras más adelante, la policía intentó dispersar la manifestación que no había sido autorizada por la prefectura, pero los manifestantes respondieron con piedras y dos tiros de arma de fuego. ${ }^{24}$

Al mismo tiempo, una manifestación yrigoyenista se había organizado en la avenida Corrientes, probablemente para tratar de contrarrestar a los liguistas a la altura de Florida. Al llegar cerca del teatro Smart, varios partidarios del presidente interpelaron al público ubicado a la salida de la sala de espectáculos: “¡¿Dónde están los revolucionarios de la Liga?!". Un grupo de republicanos replicó, lo que originó un enfrentamiento a bastonazos y disparos. Tres personas resultaron con heridas leves, entre otras el concejal yrigoyenista y presidente del comité de la sección 10 (donde sucedieron los incidentes), Raul Savaresse, y Antonio Propato, un joven de 25 años, afiliado al mismo comité. Ambos habían participado de la pelea frente al teatro. $^{25}$

El 16 de octubre, la tensión se acrecentó. La noche anterior, pegadores de carteles de la LPA habían sido identificados empapelando las paredes de las

\footnotetext{
${ }^{22}$ La Liga Patriótica y la Revolución del 6 de septiembre de 1930, Biblioteca de la Liga Patriótica Argentina, Buenos Aires, 1930, pp 7-9.

${ }^{23}$ Una fotografía del cartel se encuentra en Crítica $(08 / 10 / 1929$, p. 2) y un original del volante en U.S State Department, Argentina Internal Affairs, 835.00/442.

${ }^{24}$ La Nación, 14/10/1929, p. 1-2; La Fronda, 14/10/1929, p. 1.

${ }^{25}$ La Nación, 14/10/1929, p. 1-2; La Calle, 14/10/1929, p. 1.
} 
secciones $1^{a}$ y $3^{a}$ de la Capital con el manifiesto de la "hora de la vindicta". ${ }^{26} \mathrm{Al}$ mismo tiempo, una concentración programada por la LPA y el Comité antipersonalista Radical Acción (CRA) en la esquina de Florida y Bartolomé Mitre había sido prohibida por la Jefatura. ${ }^{27}$ Alrededor de las 18 -hora en un principio prevista por ambas organizaciones para realizar el acto- varios grupos, acompañados por los diputados personalistas de la Capital Bard, Cagnoni, Bidegain, Gerónimo Grisolía, Félix Rolando y Amancio González Zimmermann, se hicieron presentes en el lugar en medio del despliegue policial, con el objetivo de impedir que sus adversarios intentaran movilizarse. Al confirmar que ninguna reunión opositora estaba por realizarse, los militantes yrigoyenistas se reagruparon aclamando a Yrigoyen y se encaminaron en manifestación por la calle Florida al grito de "iA La Fronda!". Cuando llegaron a las oficinas de dicho diario, varios periodistas salieron a los balcones para hacer frente a la provocación. Intercambiaron insultos con los manifestantes sin que interviniera la policía. De repente, se lanzó un disparo desde la calzada. Los yrigoyenistas fueron dispersados por las fuerzas del orden, pero volvieron algunos minutos más tarde y retomaron sus invectivas contra los ocupantes del diario. Se dispararon varios tiros, esta vez desde los balcones de La Fronda ${ }^{28}$ Esa misma tarde, Crítica titulaba: “El presidente es responsable de los desbordes del Klan". ${ }^{29}$

Al día siguiente, el conflicto cobró aún mayor intensidad. Por la mañana, aparecieron varios carteles firmados "Klan Radical" en la misma esquina de Florida y Bartolomé Mitre, al igual que en otras calles del centro. Anunciaban la "supresión" próxima de "Manuel Carlés y otros enemigos de la patria". ${ }^{30}$ Sin embargo, existen dudas acerca del origen de dicho afiche cuya tipografía era igual a la "hora de la vindicta" y parecía provenir de la imprenta donde se elaboraba toda la papelería de las ligas (Pondé, 1991: 111; Rosa, 1980: 107).

Esa misma noche, un mitin opositor organizado por los Centros Culturales Lautaro (emparentados con el antipersonalismo) en la Plaza Once fue atacado por unos cincuenta yrigoyenistas armados, "secundados por los gritos y actitudes de sus compañeros situados en otros lugares de la plaza". ${ }^{31}$ El grupo rodeó a los manifestantes vivando a Yrigoyen. Después de varios disparos que provocaron el desbande de sus adversarios, los asaltantes se apoderaron de la tribuna desde donde un orador, Antonio Sturla, pronunció un discurso encendido a favor del presidente: " $i$ Ciudadanos, hemos batido al enemigo!". ${ }^{32}$ Luego, los yrigoyenistas se

\footnotetext{
${ }^{26}$ La Nación, 16/10/ 1929, p. 11.

${ }^{27}$ La Nación, 11/10/1929, p. 11.

${ }^{28}$ Crítica, 17/10/1929, p. 8; La Nación, 17/10/1929, p. 1-5; La Fronda, 17/10/1929, p. 1. La Calle, 17/10/1929, p. 1.

${ }^{29}$ Crítica, $17 / 10 / 1929$, p. 8 .

${ }^{30}$ La Nación, 19/10/1929. p. 1-3.

${ }^{31}$ La Nación, 18/10/1929, p. 1-5.

32 Véanse los partes policiales en AGPJ , Eboli, cuerpo 1, fojas 121 y 126.
} 
encaminaron en manifestación por las calles adyacentes, con el objeto de "exhibir a toda costa su dominio absoluto de la plaza y sus alrededores". ${ }^{33}$ Según La Nación, algunos dirigentes partidarios les recomendaron que se dispersaran y les pidieron que fueran al comité cercano de la 9a (Balvanera Oeste). Tanto Crítica como los partes policiales señalan que los diputados Bard, Cagnoni, Bidegain y el concejal Turano (un dirigente importante de la $9^{\mathrm{a}}$ ) estaban presentes en la plaza durante los hechos..$^{34} \mathrm{Al}$ finalizar el día, los "incidentes de la Plaza Once" dejaron un saldo de un muerto y un herido grave entre los miembros de los Centros Lautaro.

Los días siguientes, la prensa se hizo eco de las denuncias escandalizadas de la oposición que aprovechó la situación para retratar el escenario político bajo los rasgos de la peor de las "tiranías". Crítica repetía que la ciudad vivía "bajo el terror" del Klan ${ }^{35}$ y advertía que si Yrigoyen insistía "en avasallar a la Nación" el pueblo tendría "que salir a la calle a ejercitar de viva fuerza [sus] derechos constitucionales". ${ }^{36}$ Para La Fronda, el país se encontraba en "un estado manifiesto de guerra civil" ${ }^{37}$ La Nación afirmaba que el nivel de agresión empleado por el gobierno superaba el del "período más oscuro" de la historia política del país, el de Rosas, y este retroceso llevaría a la "reacción de la consciencia argentina". 38

El 24 de octubre, el PSI organizó una asamblea en el teatro argentino, invitando a todos los ciudadanos a congregarse por la "defensa del imperio de la Constitución y de la ley". Durante el mitin, el diputado Antonio de Tomaso interpeló al presidente con palabras de claro desafío: "si sus perros siguen mordiendo, sepa que los ciudadanos libres tienen el derecho de defenderse (...) ¡Y se defenderán! ¡Y sabrán tirar!"” ${ }^{39}$ El 25, fue la Brigada de la juventud de la LPA la que efectuó una concentración en la Plaza del Congreso, en "defensa de las garantías individuales". Unos días antes, la agrupación había convocado a su "Guardia Especial", compuesta por ex oficiales de policía y militares, con el objetivo de organizar la seguridad del acto. Durante la reunión preparatoria reproducida en los diarios opositores, Carlés había alentado a sus tropas recordándoles que la LPA era una organización "combatiente" dispuesta a "repeler la violencia por la violencia". ${ }^{40}$ El mes de octubre concluyó en una atmósfera de tensión y de escalada de violencia que se prolongó en noviembre con el asesinato de Carlos Lencinas en Mendoza (el cuál también fue atribuido al "Klan" por la prensa ${ }^{41}$ y el atentado fallido contra Yrigoyen en diciembre (González Alemán, 2012).

\footnotetext{
${ }^{33}$ La Nación, 18/10/1929, p. 1-5; Crítica, 18/10/1929, p. 1.

${ }^{34}$ Crítica, 19/10/1929, p. 1.

${ }^{35}$ Crítica, 18/10/1929, p. 1.

${ }^{36}$ Crítica, 20/10/1929, p. 5.

${ }^{37}$ La Fronda, 18/10/1929, p. 1.

${ }^{38}$ La Nación, 20/10/1929, p. 8.

${ }^{39}$ La Nación, 25/10/1929, p. 16.

${ }^{40}$ La Nación, 25/10/1929, p. 16.

${ }^{41}$ Crítica, 11/11/1929, p. 3 y 12/11/1929, p. 3.
} 


\section{Violencia y política}

Los acontecimientos relacionados con la figura del Klan invitan a reflexionar acerca del entramado de motivos políticos y sociales que fueron otorgando función, centralidad y legitimidad a la violencia de baja intensidad. La relación entre violencia y política no era nueva en 1929. En primer lugar porque la rivalidad entre las diversas fracciones del radicalismo solía dirimirse de esta manera en las provincias (Persello, 2004: 66-67). El crimen de la Rinconada, producido en un contexto de crisis política en San Juan, es un ejemplo paradigmático de ello. En 1921, Federico Cantoni fue acusado de ser el autor intelectual del asesinato de su adversario político, el entonces gobernador yrigoyenista, Amable Jones (que también había intentado matarlo). Ese crimen vino a colación después de un discurso pronunciado por Cantoni durante un mitin en el que alentó al público a armarse de Winchesters y de Máuseres para asesinar a su rival. Desde aquel entonces, el asesinato de Jones era recordado por los personalistas como un agravio intolerable que convertía al bloquismo en un archienemigo (Rodríguez, 1979).

En la Capital Federal, las situaciones violentas solían ser más contadas, no obstante, en cada elección, el relato periodístico de las campañas incluía algunas refriegas entre adversarios políticos. En 1918, durante la campaña por las elecciones legislativas, el socialista Vicente de Tomaso fue asesinado mientras intentaba repeler a adversarios radicales con su revólver. Durante la campaña de 1920, un incidente ocurrido en la sección $12^{a}$ terminó con la muerte de un militante radical frente a un comité socialista. En 1922, los desacuerdos entre radicales alrededor de la fórmula presidencial provocaron incidentes con uso de armas de fuego. En 1926, en plena propaganda por las elecciones de diputados, un enfrentamiento entre personalistas y antipersonalistas de la sección $2^{\underline{a}}$ terminó en un tiroteo que se saldó con tres heridos. ${ }^{42}$ También ocurrían enfrentamientos en épocas de elección de las autoridades de los comités radicales. Entre 1920 y 1924 por ejemplo, la sección 8 a fue escenario de una rivalidad entre el dirigente Antonio Bonifacio y sus competidores por la dirección del comité; el conflicto se dirimió varias veces a través de peleas con revólver en mano.

En segundo lugar, los enfrentamientos del año 1929 no pueden entenderse sin tomar en cuenta la violencia creciente que desde fines de 1927 caracterizó los términos de la política argentina a medida que se avecinaban las elecciones presidenciales. A partir de la conformación del Frente único que, en abril de 1927, selló la alianza electoral entre el antipersonalismo y los conservadores, la lucha política nacional se organizó alrededor de una polarización cada vez más feroz entre yrigoyenistas y antiyrigoyenistas. En las elecciones para la gobernación de Salta, en diciembre de 1927, los partidarios de Unión Provincial no dudaron en recurrir a múltiples maniobras ilegales y violentas para contrarrestar la campaña radical de

${ }^{42}$ La Nación, 11/01/1918, p. 8 y 04/03/1920, p. 8; La Prensa, 08/03/1926, p. 13. 
Julio Cornejo, la cual era orquestada por un grupo de personalistas porteños liderado por Molinari. En Tucumán, delegaciones conservadoras, antipersonalistas y personalistas ajenas a la provincia se inmiscuyeron en la campaña local provocando tiroteos y muertos. La situación se repitió en la provincia de Santa Fe cuyo gobernador antipersonalista, Ricardo Aldao, terminó reclamando una intervención federal para poner fin a las violencias (Biddle, 2000). En Mendoza decenas de partidarios de Yrigoyen fueron detenidos por el gobierno de Lencinas y la fase preelectoral se saldó por varios muertos, mientras que, en San Juan, las persecuciones de los cantonistas hacia los yrigoyenistas condujeron a que estos últimos se retirasen de la campaña (Rodríguez, 1979).

La ciudad de Buenos Aires tampoco fue ajena a la extensión del fenómeno. Durante la campaña de 1928, se habían subido escalones en la intensidad de la competencia: se registraron constantes disturbios y tiroteos durante las conferencias de propaganda de ambas fracciones radicales. Los incidentes provocaron por lo menos 56 arrestos, 10 heridos y un muerto, lo que llevó el comité de la Capital de la UCR a suspender la campaña antes de término. La presencia activa de Cantoni y sus matones en los mítines antipersonalistas, sus discursos virulentos, fueron percibidos por los yrigoyenistas como una provocación y una intrusión insoportable de un elemento exterior e indeseable en territorio porteño, una afrenta a la que era necesario responder. Esta situación contribuyó a exacerbar un poco más la rivalidad identitaria que oponía la UCR a los antipersonalistas. A los conflictos que involucraban a los caudillos de comité en los barrios, se sumaron enfrentamientos que reprodujeron en el escenario nacional del centro de la ciudad, un clima general de tensiones violentas que tenía lugar en muchas provincias (González Alemán, 2014).

\section{Barrio, honor y virilidad}

Más allá de la coyuntura, comprender los mecanismos de la violencia política que se desató en 1929 implica considerar la calle no solo como un espacio político, sino también social, donde se desplegaban valores y actitudes que legitimaban las actitudes bélicas. En muchos casos, los incidentes involucraban rivalidades enmarcadas en los barrios: los provocadores solían ser afiliados de un comité situado a pocas cuadras del enfrentamiento. En este sentido, los hechos atribuidos al Klan ponen en evidencia disputas de territorio controladas y ritualizadas. Se desarrollaban según una dialéctica del desafío y la réplica en función de la cual el enfrentamiento y el recurso a las armas solo intervenían en última instancia. Estos siempre eran precedidos por una serie de gestos, actitudes y palabras que constituían las etapas previas de un ritual en tres fases. Primero la interpelación verbal de los provocadores a través de la cual estos afirmaban su identidad, se presentaban a sus adversarios y los desafiaban. Luego, seguía un tiempo de espera durante el cual los contrincantes se evaluaban, se buscaban e intimidaban 
mutuamente: interpelaciones, intercambios de insultos, tentativas de acercamiento. Finalmente, el combate físico constituía la etapa última que permitía inclinar la balanza a favor de uno de los dos bandos. De hecho, estaba casi siempre precedido de la exhibición del revólver que anunciaba la predisposición de los actores al combate. En general, los tiros se disparaban al aire y es probable que el muerto de la Plaza Once fuera producto de un accidente más que de la intención de matar.

Se ve aquí ratificado un aspecto bien conocido de la relación entre política y sociedad en la Buenos Aires de entreguerra, es decir la importancia del barrio como unidad primaria de la sociabilidad y de la identidad política (Gutiérrez y Romero, 2007; De Privitellio, 2003). Sin embargo, estos hechos también permiten señalar una dimensión que ha sido menos tomada en cuenta: la existencia de cierto grado de violencia y de una lógica agonística en las prácticas políticas. En paralelo a la propaganda electoral pacificada destinada a interpelar públicos extensos, las riñas que involucraban a los afiliados más activos de los comités eran modalidades posibles de la lucha política, con un estilo muy similar a las batallas electorales decimonónicas. Hasta 1929, este tipo de violencias había sido esporádico, solía ocurrir en el marco de competencias electorales reñidas y nunca había ocupado el centro del escenario público. En 1929 en cambio, la recurrencia de estos incidentes se intensificó, cobró mayor visibilidad y resonancia, tendió a circunscribirse al centro cívico de la ciudad y, por sobre todo, se dio en el marco de un antagonismo en el que se cuestionaba la legitimidad del poder electo.

Por otro lado, conflictos y acciones violentas ponían en juego modos de interacción pública que vinculaban la virtud política con las cualidades socialmente atribuidas a la masculinidad. La política era uno de los ámbitos en que un individuo debía "actuar como hombre", es decir mostrarse públicamente apto para cumplir sus obligaciones de soldado, ciudadano y padre de familia, las cuales remitían a la capacidad de ser autónomo, afirmarse y defender lo propio. Estas expresiones públicas de virilidad eran un elemento central del estatus masculino y ordenaban las relaciones en el bar, el comité, el club de fútbol, etc. Se desplegaban en toda su dimensión a través de los actos de obstrucción de conferencias o las refriegas callejeras: allí, los actores hacían demostración de comportamientos impregnados de los valores físicos y morales agonísticos. "Tomar" la calle era una afirmación pública de virilidad, es decir, de valentía, ardor, destreza, espíritu de conquista, frente a la amenaza que podían representar los rivales (Tosh, 1994: 184; Sohn, 2009; Frydenberg, 2011: 145-150; Gayol, 2007).

Más aún, la palabra "viril" en política solía remitir a un conjunto de valores atribuidos al ciudadano-soldado. Se refería a la virtud de los hombres libres capaces de actuar con determinación en la vida pública, demostrar espíritu de sacrificio y de levantarse en armas para defender la patria. Se oponía a la apatía cívica y se asociaba a la idea de regeneración nacional. Este ideal de masculinidad republicana definía normas de conducta para el derecho de ciudadanía y constituía un capital necesario para lanzarse en la arena pública. 
Según esta lógica, la actividad política ponía en juego el honor de los que se involucraban en ella (Gayol, 2008). Para los actores observados, actuar como ciudadano, como radical y como hombre suponía dar a conocer opiniones propias y defenderlas con brío, influir en los debates públicos e intervenir "virilmente" en situaciones consideradas inaceptables $\mathrm{u}$ ofensivas. La participación ciudadana no se agotaba en el acto electoral, sino que -antes y después- implicaba una acción constante en el espacio público. En ese marco, las actitudes violentas podían gozar de legitimidad si el contexto lo ameritaba. En 1929 justamente, el carácter irreductible del conflicto entre yrigoyenistas y antiyrigoyenistas había convertido la lucha política en una cuestión de honor que no podía limitarse a los aspectos discursivos y procedimentales.

Así, en un discurso ante el Congreso, el diputado de la UCR Romeo Saccone presentó el funesto "incidente de la Plaza Once" del 17 de octubre de 1929 como una respuesta legítima de los yrigoyenistas del barrio. Estos habían sido ofendidos por la presencia de un mitin opositor en "su" territorio, solo tres días después de que el presidente personalista de la sección, el concejal Savarese, hubiera quedado herido tras un enfrentamiento con liguistas de la LR. La oposición se había ido "a la misma parroquia del herido para hacer más ofensiva y desafiante la situación", por lo que se había producido "la reacción consiguiente" de los radicales. "Yo pregunto a los hombres de dignidad, que tienen amor propio -agregó Saccone-, ¿quién se va a dejar abofetear o mofar sin un gesto de reacción? Ni una mujer es capaz de soportar semejante baldón".

Asimismo, Saccone retrató la actuación de Savarese en términos heroicos, insistiendo en que este último había sido herido por sus contendientes por negarse a gritar “iMuera Yrigoyen!". Tal aclaración procuraba reparar la ofensa provocada por la crónica que Crítica le había dedicado al mismo acontecimiento: el diario opositor había llegado a cuestionar la virilidad de los personalistas, sosteniendo en tono jocoso que el concejal había sido herido por un correligionario "que se había equivocado en su puntería". A su vez, refiriéndose a su propia reacción frente al espectáculo ofrecido por la actividad de los integrantes de la LR en la calle Florida, el diputado confesaba: "Yo he pasado por la calle Florida en ciertas tardes y confieso con dolor que mi primer acto de prevención fue tomar un automóvil para volver a mi casa. ¿Sabe señor a qué? A cargar mi revólver y llevar una caja de balas de repuesto". ${ }^{43}$

Así, las situaciones violentas atribuidas al Klan dejan entrever códigos y prácticas vinculados a un régimen ofensivo de masculinidad que implicaba tanto a dirigentes como a partidarios rasos. Por un lado, la participación en la calle involucraba a actores comprometidos individual y colectivamente en la representación y la defensa del universo de pertenencia política frente a los competidores. Por el otro, la defensa del honor modelaba las prácticas y la trama

${ }^{43}$ Diario de sesiones de la Cámara de Diputados, Congreso Nacional, 20/11/1929, p. 188-220. 
argumentativa de la acción política. El sentido del honor obligaba a los varones a vengar tanto las afrentas personales como las ofensas al grupo de partidarios y a Yrigoyen; en particular cuando estas afrentas eran interpretadas como una provocación en el territorio propio de acción. Estos códigos no eran exclusivos del radicalismo (cf. los discursos de Carlés y De Tomaso o las prácticas de la LR), pero cobraban mayor visibilidad en el caso de los yrigoyenistas: primero, porque en Buenos Aires, la UCR tenía mayor capacidad de convocatoria que la oposición, se encontraba en "su" territorio y lo tenía que defender; segundo, porque la prensa era opositora casi en su totalidad $\mathrm{y}$, a través de ella, cualquier acción ofensiva del radicalismo era instrumentalizada por los antiyrigoyenistas para pintar un escenario de casi guerra civil; tercero, porque el ideal revolucionario y combativo era un componente fuerte de la identidad radical que impregnaba las prácticas de los partidarios (Reyes, 2015). En este sentido, se relacionaba con una forma específica de concebir la acción democrática.

\section{La disputa por el centro}

\section{La sustancialización de la vida pública}

Si bien las prácticas violentas encuentran unidad en la lógica del honor, la centralidad que estas cobraron en 1929 se explica por la radicalización del conflicto político y por su anclaje en el espacio urbano. Como lo vimos, a raíz del debate sobre los diplomas, diferentes sectores antiyrigoyenistas apuntaron a crear un clima de agitación sediciosa en las calles de la ciudad. Esa acción contestataria era presentada como un deber de los ciudadanos, por encima de los mecanismos formales de "defender la Constitución y la República" cuya integridad se consideraba amenazada por el gobierno. Esos llamados cada vez más abiertos a la rebelión, al grito de “¡Viva la revolución!”, “¡Abajo el Peludo!” o “¡Muerte a Yrigoyen!", contribuyeron a endurecer la lucha por la ciudad, por lo que la gravitación de la figura del Klan también debe ser entendida en este contexto (González Alemán, 2012).

Las movilizaciones opositoras tuvieron como escenario principal el centro de la capital. La "reacción cívica" contra la "tiranía" de Yrigoyen no suponían un objetivo electoral inmediato, por lo tanto, no había necesidad de aventurarse más allá para movilizar en los barrios. Más aun, la mayoría de las concentraciones opositoras no superaban los dos mil manifestantes. Ese número era suficiente para “agitar la opinión" en el corazón del escenario cívico nacional y así reactivar la figura de la resistencia al despotismo. En el espacio reducido de la ciudad decimonónica, se reactualizaba una forma de acción pública protagonizada por los "hombres virtuosos", los que eran "capaces" de levantarse en defensa de las libertades republicanas. A su vez, dichas movilizaciones limitadas a pocas cuadras eran amplificadas por las crónicas y los editoriales de los principales órganos de la prensa nacional. Los diarios contribuían a fijar los temas de la contestación, a 
difundir los argumentos intelectuales de la lucha, pero también a convocar, alimentar y dramatizar la dinámica beligerante en la calle. También participaban materialmente en la construcción de los espacios de movilización, ya que sus oficinas eran puntos de referencia de los itinerarios de los grupos en lucha. Además, los dueños de diarios solían ser parte integrante de la acción colectiva como manifestantes notables y oradores.

El rol de la prensa era el reflejo de la importancia ocupada por la figura de la "opinión", en el marco de un sistema electoral ampliado que no había saturado, sin embargo, el campo de la representación. Opinar era un acto cargado de una dimensión performativa: suponía encarnar su propia palabra y defenderla, instar a la acción cívica, sumar adhesiones al combate político y pesar sobre las decisiones de la autoridad electa (Palti, 2007; Hirsch, 2013; Rojkind, 2017). En el contexto de 1929, esta dimensión se intensificó al punto que el espacio urbano se había convertido en una metáfora de la polis. Los discursos parlamentarios denunciaban la violencia callejera de los adversarios y llamaban a la réplica. Los afiches invadían el centro, se respondían en tono amenazante e incitaban a la vindicta. Desde los balcones de Crítica se habían arrojado letras de plomo sobre manifestantes yrigoyenistas y, en dos ocasiones, La Época y Klan Radical llamaron a que los ciudadanos incendiaran las oficinas del diario de Botana en signo de "manifestación soberana". ${ }^{44}$ En definitiva, tomar la palabra significaba una fuerza actuante y una presencia efectiva de soberanía susceptible, en última instancia, de determinar la suerte del gobierno. Ambos bandos participaban de esa sustancialización de la vida pública en términos agonísticos. En el marco de tales disputas estratégicas en y por el espacio público, valía imprimir falsos afiches para desacreditar al adversario y magnificar la violencia callejera atribuyéndosela a un misterioso grupo de choque radical.

\section{Democracia de la acción}

La concepción del espacio público en sentido restringido activada por la oposición se revelaba problemática en el marco de la ampliación electoral y del sistema de partidos establecidos desde 1912. Interrogado por Caras y Caretas sobre la actividad de la oposición en la ciudad, el senador yrigoyenista Diego Molinari lo subrayaba en febrero de 1930: "No la he visto", y "si la hay no pasa de la calle Florida, y usted comprenderá que 'eso' no es toda la capital. [...] La oposición no llega, pues, a la periferia de la ciudad, que es donde los votos deciden una lucha electoral". ${ }^{45}$ Para el representante de la UCR, la legitimidad primaria de la acción política se ubicaba en otro plano, el del "plebiscito" a Yrigoyen ratificado en 1928 por el voto del conjunto de la ciudad (y del país), es decir de las secciones electorales de los barrios más

\footnotetext{
${ }^{44}$ Crítica, 28/12/1929, p. 1; Klan Radical, 10/05/1930, s. p.

${ }^{45}$ Caras y Caretas, 22/2/1930, núm. 1638, p. 67.
} 
poblados y alejados del centro. Según esta lógica, la presencia de unos pocos en el espacio cívico de la capital carecía de representatividad democrática.

Más aún, la opinión contraria al gobierno desplegada en acción para vivar a la revolución y lanzar mueras a Yrigoyen se convertía en incitación a la sedición y en expresión de desacato por su contenido injurioso y su hostilidad radical a la figura presidencial. A los ojos de los yrigoyenistas, las movilizaciones opositoras salían de las formas legítimas para la participación en la calle: los que intervenían en ella llamaban a "erguirse" y se afirmaban en depositarios de la defensa de las libertades republicanas. Al pretender expresar una presencia efectiva de soberanía, rivalizaban performativamente con las autoridades que emanaban de la "voluntad electoral". Estas afrentas a la "voz del pueblo" justificaban respuestas reparadoras. El pueblo, "con su voto consciente y libre", había concurrido a "elegir el actual gobierno de la República" por considerar "a los hombres que lo integraban, como los más genuinos representantes de la democracia argentina" ${ }^{46}$

En lo discursivo, reaparecía la gramática del honor como fundamento de las acciones violentas. En su análisis de los incidentes de octubre de 1929, el diario $\mathrm{La}$ Calle señalaba la "responsabilidad originaria" de la oposición que "fatalmente" había engendrado el episodio funesto de la plaza Once. "El tono insolente y deslenguado, que llega a la procacidad más virulenta e irritante, con que la prensa llamada de oposición" se había dedicado a combatir al gobierno y los "conceptos biliosos, sobrecargados de dicterios y de sarcasmos" repetidos "de modo irresponsable en las plazas y en las calles públicas por patotas de 'niños mal de casa bien'" habían suscitado "las condignas reacciones del pueblo". ${ }^{47}$ De la misma manera, en su discurso pronunciado en la Cámara de Diputados, Saccone celebraba la manifestación "viril" realizada por sus correligionarios frente a las oficinas de $\mathrm{La}$ Fronda el 16 de octubre: "Los radicales no podíamos ir a la calle Florida", justificó, "los engominados de no sé qué Liga se habían posesionado del centro de la ciudad". Estas patotas habían generado "más de quince incidentes" por exigir que se gritara “iMuera Irigoyen!” a transeúntes a quienes calificaban de yrigoyenistas; "el que no los complacía iba al hospital magullado y lleno de contusiones". Por este motivo, un grupo de jóvenes radicales, "cansados, hastiados de la bíblica mansedumbre, deseosos de no seguir ofreciendo la mejilla derecha cuando se les golpeaba la izquierda", se había constituido en la calle Florida "para demostrar a esos audaces que la calle es para todos y que en caso de ser para algunos sería siempre para la mayoría y no para las pequeñas minorías aristocráticas". ${ }^{48}$

En los discursos de Saccone y Molinari, la ocupación por unos pocos de las calles del centro, espacio tradicional de las movilizaciones decimonónicas, constituía una apropiación aristocrática en un mundo democrático garantizado por el

\footnotetext{
${ }^{46}$ La Calle, 19/10/1929, p. 1.

${ }^{47}$ La Calle, 19/10/1929, p. 1.

${ }^{48}$ Diario de sesiones de la Cámara de Diputados, Congreso Nacional, 20/11/1929, p. 188-220.
} 
yrigoyenismo. Por lo tanto, ir al enfrentamiento equivalía a una intervención justiciera orientada a defender el honor de los radicales, reparar una apropiación ilegítima del espacio público y restituir el derecho del "pueblo" (entiéndase mayoría electoral) a ocupar la calle.

El primer afiche del Klan Radical referido a las investiduras de los senadores del Cuyo puede ser leído a la luz de esta concepción. Durante la campaña de 1928, las persecuciones de los cantonistas y lencinistas hacia los yrigoyenistas habían sido patentes. Para los personalistas, Cantoni y Lencinas habían "avasallado el espíritu de la democracia nacional". ${ }^{49}$ En 1929, sus discursos encendidos en el recinto parlamentario y el apoyo que recibían de la oposición constituían otra afrenta más a la soberanía popular expresada en el "plebiscito". El valor democrático personificado por el presidente no podía sino ser reafirmado por el Senado mediante la denegación de los diplomas; de lo contrario, como lo afirmaba el cartel, tendría "que enfrentar a muchos argentinos, dispuestos al sacrificio en salvaguardia de la dignidad nacional".

En definitiva, las prácticas y los discursos de los yrigoyenistas producían una forma de hacer política en tiempos de masificación que operaba una ecuación entre república y democracia. La calle era un espacio donde la acción ciudadana podía reeditar el "plebiscito" de 1928 para contrarrestar las amenazas. El análisis de La Calle sobre los incidentes ocurridos en los alrededores del Congreso en julio de 1929 es significativo de esta lógica: "La conciencia cívica" recurría nuevamente "a la actitud combativa" y el radicalismo estaba "de pie nuevamente para jugar la gran partida del honor nacional, amenazado por oligarcas y traidores". El "pueblo en movimiento" y "la juventud partidaria" alzaban "otra vez los claros colores de la bandera histórica" y se lanzaban "a la calle a hacer respetar la Constitución y la dignidad del país". "No sabemos quienes son ni dónde están los que acaban de recoger nuestro llamado a la acción, pero bajo ese expresivo lema de 'Clan Radical'", concluía el diario, “damos por presente al millón de ciudadanos que afirmó la soberanía cívica de nuestra democracia". ${ }^{50}$

El 3 de agosto, durante una manifestación en Avenida de Mayo para celebrar el rechazo de los diplomas del Cuyo por el Senado, el director de La Calle, Gastón Bernard, arengó a los manifestantes recordándoles “el apotegma que el doctor Yrigoyen sostiene toda vez que se recaba su palabra frente a los acontecimientos: hay que ser radical en todo. No solo es necesario demostrarlo en la hora del comicio cuando se deposita el voto". La acción debía ser "constante y persistente", a fin de "exterminar las alimañas emboscadas para lograr sus mezquinas aspiraciones". Solo así podría "realizarse íntegramente la aspiración democrática". ${ }^{51}$ En la misma línea, un poema publicado en el diario Klan Radical a principios de 1930 definía al

\footnotetext{
${ }^{49}$ La Época, 11/10/1929, p. 3.

${ }^{50}$ La Calle, 05/07/1929, p. 1.

${ }^{51}$ La Calle, 03/08/1929, p. 3.
} 
"personalista" como un "hombre-acción" capaz de "alzar el civismo" cuando fuese necesario. ${ }^{52}$

La "cultura de la revolución", componente original de la "religión cívica" radical, impregnaba la concepción democrática formulada en los discursos yrigoyenistas, pero en una perspectiva invertida con respecto a la de los primeros tiempos. Surgida de la confrontación con el orden conservador, la UCR había forjado su identidad "en oposición a", reivindicando la revolución como medio para devolver al "pueblo" los derechos usurpados por los hombres del Partido Autonomista Nacional y regenerar la política. El postulado de un combate decisivo entre la "Causa" radical y el "Régimen oligárquico" tendía a resumir los desafíos que animaban el escenario político imaginado por los radicales y justificaba la existencia misma del partido. En 1929, esta vez desde el gobierno, los partidarios de Yrigoyen postulaban la democracia como una ciudadela perpetuamente asediada. A pesar de la restauración de los mecanismos democráticos garantizada por el acceso del líder a la presidencia, el "pueblo" debía permanecer levantado, alerta, "en guardia", hacer demostración de su espíritu cívico y estar dispuesto a levantarse contra aquellos que amenazaban la democracia. ${ }^{53}$ La combatividad en la calle, es decir la defensa por medio de la acción del ideal regenerador del radicalismo, constituía otra forma de expresión legítima de la "voluntad popular". En paralelo al ejercicio procedimental del voto a través del que se producía el "plebiscito", la demostración tangible de la voz del pueblo debía funcionar como una instancia permanente de control y de defensa de las instituciones.

La figura del Klan Radical debe entenderse en este contexto de radicalización del yrigoyenismo y de su concepción de la representación democrática, a medida que esta se veía amenazada por la movilización creciente y encarnizada de la oposición. El vaivén constante entre las proyecciones alarmistas de la prensa, la realidad de la acción política en la calle y el endurecimiento de las posturas de ciertos integrantes de la UCR contribuyeron a dar cuerpo a lo que, quizás en un primer momento, parecía existir solo a través de unos afiches provocativos.

\section{Consideraciones finales}

El año 1929 corresponde a un momento de crisis política caracterizado por una polarización absoluta entre yrigoyenistas e antiyrigoyenistas. En este contexto, cada bando postuló la lucha en términos irreductibles arrogándose el monopolio de la defensa y de la regeneración de las instituciones republicanas. Esta lógica encontró su expresión en las prácticas concretas de los actores: se caracterizó por la recurrencia de acciones violentas de baja intensidad orientadas hacia la anulación simbólica del adversario en las calles. Estos enfrentamientos ponían en evidencia un

\footnotetext{
${ }^{52}$ Klan Radical, 15/02/1930, p. 3.

${ }^{53}$ La Época, 14/08/1929, p. 1.
} 
modo de participación política impregnado de valores derivados de los códigos sociales del honor masculino, entrecruzados con una concepción de la ciudadanía que remitía a la tradición republicana y valoraba las expresiones "viriles" en el espacio público.

Los trabajos sobre la relación entre honor y política a fines del siglo XIX suelen señalar que la década de 1910 corresponde a un período en que la lucha política se fue despojando de la impronta de los códigos del honor (Gayol, 2008; Piccato, 1999). Por otro lado, los estudios enfocados en la construcción de una ciudadanía electoral ampliada a partir de la reforma de 1912 suelen desatender este tipo de problemáticas. No obstante, los casos estudiados relacionados con la figura del Klan permiten sostener que, a fines de los años 1920, la violencia podía constituir un elemento constitutivo y legítimo de la praxis política, aunque la forma en que se conectaba con la virilidad se había modificado. Las "cuestiones de honor" se vinculaban con nuevas prácticas, valores políticos y sociales que las adaptaban al nuevo orden democrático. Por un lado, el desarrollo de los barrios y de ámbitos de sociabilidad masculina como el club o el comité, así como el sistema de partidos, fueron componiendo otro tipo de identidad que tendió a involucrar al individuo en tanto integrante de un grupo más amplio. En este contexto, la participación política por medio de la acción involucraba a actores comprometidos colectivamente con un comité local, un caudillo barrial, un partido o un líder. Los individuos acusados de pertenecer al Klan son una expresión de este fenómeno.

Finalmente, el análisis del conflicto callejero atribuido al Klan Radical permite restituir la dimensión agonística del campo político no cómo una supuesta desviación con respecto a un deber ser que se encarnaría en el ideal deliberativo de la política liberal sino como uno (no el único) de los componentes de las cosmovisiones de los actores. El sistema representativo ampliado por la reforma Saenz Peña convivía con una faceta que asimilaba la política a "una forma ritualizada de guerra, una suerte de sublimación del antagonismo" mediante el recurso a enfrentamientos verbales con vocación performativa (Palti, 2007: 200-201). En ese marco, el coraje o la disposición al combate podían ser tan valorados como los comportamientos "civilizados" del "elector consciente". La acción cívica se asociaba al deber de expresar "virilmente" convicciones en el espacio público. La palabra "viril" remitía a la virtud de los hombres libres, los que eran capaces de ejercer su soberanía, de intervenir con determinación en la vida pública a favor del bien común, de demostrar su espíritu de sacrificio y de levantarse en armas para defender la patria de un poder arbitrario. Sin embargo, la prédica yrigoyenista había reconfigurado los términos de esta matriz republicana, adaptándola al nuevo escenario democrático.

El lenguaje y los sentidos otorgados por los yrigoyenistas a la acción remitían constantemente al mito fundacional de la revolución/reacción cívica como fuente y motor de la regeneración democrática en marcha. La virtud cívica no solo pasaba por el mero hecho de ir a votar, sino también por demostrar la existencia de un alma 
democrática en movimiento, mediante la participación activa en los asuntos comunes y en la lucha contra la amenaza de "minorías aristocráticas". A su vez, dicha matriz había sido reconfigurada en el marco de un campo político ampliado: el yrigoyenismo articulaba el motivo de la revolución con la prueba de la mayoría electoral. La regeneración democrática se realizaba a través de la identificación entre reacción cívica, mayoría electoral y partido/líder. Por lo tanto, la esencia de la democracia se encarnaba en la visibilidad del pueblo-actor en tanto fuerza inmediatamente activa de la soberanía frente a quienes amenazaban corromper la comunidad nacional. El análisis del Klan radical, real o fantaseado, permite un acercamiento a dicha concepción de lo político.

Buenos Aires, mayo de 2020.

\section{Fuentes impresas}

"Eboli, Enrique Fernando María y Lopez Serrot, Oscar", Sentencia en lo Criminal letra "D".

Beresford Crawkes (1932). 533 días de historia argentina, Imprenta Mercatali, Buenos Aires.

Diario ;Libertad!, 3 de julio de 1929.

Diario Crítica, 4 y 26 de julio de 1929; 17, 18, 19 y 20 de octubre de 1929; 11 y 12 de noviembre de 1929; 28 de diciembre de 1929.

Diario de sesiones de la Cámara de Diputados, Congreso Nacional, 20 de noviembre de 1929.

Diario La Calle, 4 y 5 de julio de 1929; 3 de agosto de 1929; 14, 17 y 19 de octubre de 1929.

Diario La Época, 3 y 4 de julio de 1929; 14 de agosto de 1929; 11 de octubre de 1929.

Diario La Fronda, 14, 17 y 18 de octubre de 1929.

Diario La Nación, 11 de enero de 1918; 4 de marzo de 1920; 8 de marzo de 1926; 3 de julio de 1929; 11, 14, 16, 17, 18, 19, 20 y 25 de otubre de 1929.

Diario La Prensa, 8 de marzo de 1926.

Diario La Vanguardia, 3 de julio de 1929.

La Liga Patriótica y la Revolución del 6 de septiembre de 1930, Biblioteca de la Liga Patriótica Argentina, Buenos Aires, 1930.

Oyhanarte, Horacio (1932). Por la patria, desde el exilio digo, Biblioteca "Democracia Radical", Buenos Aires.

Revista Caras y Caretas, 22 de febrero de 1930, núm. 1638. 
Revista Klan Radical, 15 de febrero de 1930 y 10 de mayo de 1930.

\section{Bibliografía citada}

Arlt, Roberto (1928). "La sociedad secreta, capítulo inédito de Los siete locos", en Pulso. Revista de Arte de Ahora, núm. 1.

Biddle, Nicholas (2000). "Hipólito Yrigoyen, Salta, and the 1928 Presidential Campaign", en Brennan, James P. y Pianetto, Ofelia (eds.) Region and Nation: Politics, Economics, and Society in Twentieth-Century Argentina, New York: Palgrave Macmillan, pp. 71-101.

Borges, Jorge Luis (2011). Textos recobrados, 1931-1955, Buenos Aires: Emecé.

De Privitellio, Luciano (2003). Vecinos y ciudadanos. Política y sociedad en la Buenos Aires de entreguerra, Buenos Aires: Siglo XXI.

Frydenberg, Julio (2011). Historia social del fútbol, Siglo XXI, Buenos Aires, Siglo XXI.

Gayol, Sandra (2007). Sociabilidad en Buenos Aires. Hombres, honor y cafés, 1862-1910, Buenos Aires: Ediciones del Signo.

Gayol, Sandra (2008). Honor y duelo en la Argentina moderna, Buenos Aires: Siglo XXI.

González Alemán, Marianne (2012). “El conflicto callejero porteño y el derecho de reunión durante la segunda presidencia de Yrigoyen", en PolHis, núm. 9, disponible en: http://historiapolitica.com/datos/boletin/Polhis9_GONZALEZALEMAN.pdf

González Alemán, Marianne (2014). “Ciudadanos en la calle. Violencia, virilidad y civilidad política en la campaña presidencial porteña de 1928", en Hispanic American Historical Review, núm. 3, vol. 94, pp 421-453.

Gutiérrez, Leandro y Romero, Luis Alberto (2007). Sectores populares, cultura y política. Buenos Aires en la entreguerra, Buenos Aires: Siglo XXI.

Halperín Donghi, Tulio (2007). Vida y muerte de la República verdadera (1910-1930), Buenos Aires: Emecé.

Hirsch, Leonardo (2013). “La resurrección retórica de la república en 1890. Un análisis sobre las relaciones entre elocuencia, oratoria y política en Argentina a fines del siglo XIX", en Boletín del Instituto de Historia Argentina y Americana "Dr Emilio Ravignani", núm. 38, pp.108-137.

Horowitz, Joel (2015). El radicalismo y el movimiento popular, Buenos Aires: Edhasa.

Jaume, Lucien (2004). “El pensamiento en acción: por otra historia de las ideas políticas", en Ayer, núm. 53, pp. 109-130.

Jauretche, Arturo (2002). Escritos inéditos, Buenos Aires: Corregidor.

Lepoutre, David (1997). Cour de banlieue : codes, rites et langages, Paris : O. Jacob. 
Mustapic, María (1984). “Conflictos institucionales durante el primer gobierno radical: 1916-1922”, en Desarrollo Económico, núm. 93, vol. 24, pp. 85-108.

Palti, Elías (2007). El tiempo de la política. El siglo XIX reconsiderado, Buenos Aires: Siglo XXI.

Persello, Ana Virginia (2001). “Administración y política en los gobiernos radicales, 1916-1930", en Sociohistórica, núm. 8, pp. 121-152.

Persello, Ana Virginia (2004). El Partido Radical Gobierno y oposición, 1916-1943, Buenos Aires: Siglo XXI.

Piccato, Pablo (1999). “La política y la tecnología del honor: el duelo en México durante el porfiriato y la revolución", en Anuario IEHS, núm.14, pp. 273-294.

Pondé, Eduardo Bautista (1991). Los reelegidos. Roca, Yrigoyen y Perón, Buenos Aires: Legasa.

Reyes, Francisco (2015). “La revolución como mito, la regeneración como promesa. Ideas-fuerza en los orígenes de la Unión Cívica Radical", en Ariadna histórica, vol. 4, pp. 117-146.

Rock, David (1972). "Machine Politics in Buenos Aires and the Argentine Radical Party, 1912-1930", en Journal of Latin American Studies, núm. 2, vol. 4, pp 233-256.

Rock, David (2010). El radicalismo argentino. 1890-1930, Buenos Aires: Amorrotu.

Rodríguez, Celso (1979). Lencinas y Cantoni. El populismo cuyano en tiempos de Yrigoyen, Buenos Aires: Editorial de Belgrano.

Rojkind, Inés (2017). “Campaña periodísticas, movilizaciones callejeras y críticas al gobierno. La participación política en el Orden conservador", en Investigaciones y Ensayos, núm. 65, pp. 113-134.

Rosa, José María (1980). Historia argentina, Vol. 11, Buenos Aires: Granda.

Saítta, Sylvia (2013). Regueros de tinta. El diario Crítica en la década de 1920, Buenos Aires: Siglo XXI.

Sohn, Anne-Marie (2009). "Sois un homme!". La construction de la masculinité au XIXe siècle, Paris : Seuil.

Tato, María Inés (2004). Viento de Fronda. Liberalismo, conservadurismo y democracia en la Argentina, 1911-1932, Buenos Aires: Siglo XXI.

Tosh, John (1994). "What Should Historians Do with Masculinity? Reflections on Nineteenth-Century Britain”, en History Workshop, núm. 38. 